\title{
The Financial Decision Making for Tourism Hotels: Applying Real Options Approach
}

\author{
Tung-Li Shih ${ }^{1}$, Yu-Feng Chang ${ }^{2} \&$ Tyrone T. Lin ${ }^{3}$ \\ ${ }^{1}$ Assistant Professor, Department of Hospitality Management, MingDao University, Taiwan \\ ${ }^{2}$ Master, Department of International Business, National Dong Hwa University, Taiwan \\ ${ }^{3}$ Professor, Department of International Business, National Dong Hwa University, Taiwan \\ Correspondence: Tung-Li Shih, Assistant Professor, Department of Hospitality Management, MingDao \\ University, No.369, Wen-Hua Rd., Pitou, ChangHua 52345, Taiwan. Tel: 886-048-876-660. E-mail: \\ tungli@mdu.edu.tw
}

Received: December 17, 2019

Accepted: January 9, 2020

Online Published: January 20, 2020

doi:10.5539/ijef.v12n2p32

URL: https://doi.org/10.5539/ijef.v12n2p32

\begin{abstract}
This paper is to evaluate the optimal threshold value for operating income uncertainty dealt with the investment strategy in tourism industry investor into Sun Moon Lake international tourist hotel market. To price the optimal project value and to provide strategy manager for another decision way of thinking is the focal point in this paper. The way of utilizing the real options approach to assess two periods' optimal investment strategies for chartered company, to analysis the optimal investment timing for the first period and the second period and to build the optimal two periods' investment evaluation model. The proposed model is to find the optimal thresholds for the first period and the second period under value-matching and smooth-pasting conditions and to discuss the impact of model parameters upon the investment thresholds for the first period and the second period by numerical analyses. The conclusions provide some valuable references for chartered company to make decisions with a new way of thinking for investment project.
\end{abstract}

Keywords: tourist hotel, real options approach, investment thresholds

\section{Introduction}

\subsection{Research Background}

Tourism industry has become the most social and economic indicator of the industry in every country in twenty-first Century, and it is also an important industry for our country to promote private sectors participation in public infrastructure. With widespread of the domestic recreation tourism, the number of tourists has increased rapidly. Also, the opening to mainland tourists travelling to Taiwan has brought more and more visitors to Taiwan, and hence the government has been actively developing the tourism and leisure infrastructure and facilities to create high quality tourism environment. However, the government financial ability to public infrastructure has been under the burden since the definition and modes of tourism were innovated continuously. Therefore, if incorporating the advantages of private enterprises, such as the financial resources, efficiency of executive management, new marketing strategies and innovative business philosophy, the government is able to create tourism facilities with high quality and efficient management and provide better leisure tourism environment under limited expenditure.

According to the statistics from Tourism Bureau, in recent five years, the rate of domestic tourism has increased from $90 \%$ in ROC year of 93 (2005) to $92.5 \%$ in ROC year of 97 (2009) which shows that domestic tourism has been popularity. The average number of annual travelling in recent five years was 5.27 times, average days of stay was 1.6 days, and the average ratio of holiday travel was over $70 \%$. From the figures, it represents that tourism is no longer just for rich people but for general public people as well which it has become popular to use the weekends for leisure activities. Moreover, tourism industry is a key smokeless industry for countries around the world and it is also one of star industries like IT (Information Technology) industry in $21^{\text {st }}$ Century, which it has obvious benefits in creating job opportunities and gaining foreign currencies. According to the estimation from World Travel and Tourism Council (WTTC), the growth of global tourism industry in the future 10 years will be: tourism expenditure will increase from US\$4.21 million to US\$8.61 million; the contribution rate of 
tourism industry to GDP will raise from 3.6\% to 3.8\%; the employment will grow from the current 198 million to 250 million. Except for double tourists plan promotion to Taiwan in ROC (Republic of China) year of 96 (2008) and 97 (2009), the Executive Yuan has planned the tourism industry as the key development industry in the future since the beginning of ROC year of 98 (2010).

Because tourism revenue in Taiwan accounted for less than 1.4\% of GDP, compared with more than $2.5 \%$ in European countries and $6 \%$ in Asian countries such as Singapore, Malaysia, and Thailand, the Executive Yuan has planned to promote "Tourism Top-Notch Pilot Program" since ROC year of 98 (2010) to develop international tourism, improve the quality of domestic tourism and increase the foreign currencies income through the inspections from aspects of resources, market, industry and people and the current tourism administrative segmentation. The purposes of the Program are to actively build Taiwan to become the "East Asian Tourism Exchange Transshipment Center" and "Key International Tourism Destination". And it is also expected to create NT $\$ 550$ billion tourism income in 2012 of which there will be about NT $\$ 300$ billion tourism foreign currency earnings (more than $2 \%$ of GDP) and national tourism will be increased to NT $\$ 250$ billion which further drives 400,000 direct and indirect tourism employment and investment from private enterprises. The number of visitors to Taiwan has reached to 3,850,000 since ROC year of 97 (2009) which created NT \$195 billion tourism foreign currency income and NT \$184 billion from domestic national tourism. It shows that there is great development space in Taiwan's tourism market. According to the survey on tourism consumption and tendency of visitors to Taiwan in 97 year of the Republic of China, Taiwan scenery is one of the main factors attracting foreign tourists to travel to Taiwan, especially Sun Moon Lake tourism scenic area has been one of the top five sight spots in history. Sponsored by the Ministry of Transportation and Communications (MOTC), the Sun Moon Lake National Scenic Area Administration was authorized to take "Sun Moon Lake Hsiangshan/Xiangshan Tourism Hotel BOT Project" into effect in January 98 (2010). The current the number of hotel rooms of Sun Moon Lake surrounding area is 2,194, and while the accommodation demand forecast for ROC year of 101 (2013) was expected to 3,336 rooms, and hence the current accommodation facilities of Sun Moon Lake area have been unable to meet the future demand. Therefore, in terms of long term development plan, the Sun Moon Lake National Scenic Area Administration has commenced to plan on development project of Sun Moon Lake Hsiangshan/Xiangshan tourism hotels expecting to attract private investments through BOT method in order to enhance the tourism development of Sun Moon Lake and strengthen international level of service standard.

\subsection{Research Motivation/Problem}

With the fast development of world economy, governments all over the world have increased their demand in public infrastructures which made increase of the public sector spending and hence their expenditure on public sectors grew significantly and caused the government's fiscal burden. However, insufficient supervision of the public sectors has caused low efficiency of construction and poor business performance which is the big problem for every government management; relatively, it is better for public sectors to have involvement of private sectors in infrastructure development and incorporation with their effective business management.

The characteristics of public infrastructure projects are large investment, high risk, and low return rate. Although not all public works have high rates of return or compensation rates, most of them can create considerable external benefits and social benefits. In order to strengthen the willingness of private participation in major public infrastructure, the government is committed to the introduction of international popular BOT (Build Operate, Transfer) model, hoping the cooperation between public and private sectors to inject the technology, ability and efficiency of private sectors, and to enhance the quality of infrastructure and increase the social welfare.

In order to strengthen the willingness of private sectors participation in BOT projects, the government offers various incentives, including assisting private sectors in acquiring private lands, providing long-term financing and tax preference, and etc. The purposes of these substantial measures are to enhance public welfare and to provide public services to the public through infrastructures. On the other hand, it can avoid the unbalance of the interest between private sectors and government agencies as the government departments should provide proper supervision on the operation of infrastructure planning to make sustainable operation of established infrastructures by private sectors in order to achieve the balance of public interest and private interest.

Tourism hotel BOT project was initially to promote the development of public infrastructures and the channel to make sure the participation of the private enterprises. However, there is little relevant financial research about tourism hotels BOT projects on how much capital shall be invested to the new investment projects. BOT is one of the investment modes of private sectors participated infrastructures. BOT is the abbreviation of 
Build-Operate-Transfer, and its original definition is that private sectors invest to build public infrastructure and obtain the authorized operation right and ownership, and recover the investment for a certain period. The facility will be then transferred to the public administration at the end of the concession agreement. Therefore, infrastructure is public goods in the economics. Public goods have two characteristics as nonrival and nonexclusive. Nonrival means that non-rival goods may be consumed by one consumer without preventing simultaneous consumption by others. A good or service is non-exclusive if non-paying consumers cannot be prevented from accessing it. So goods that are both nonrival and nonexclusive are called public goods. Goods with only nonrival are known as the quasi-public goods. Because of nonrival and nonexclusive characteristics of public goods, it only can internalization of externalities through government subsidies and tax. And therefore, the government can create a suitable objective environment for market activities through the implementation of proper public policy and make comprehensive economic laws and regulations. On the one hand, there are serious obstacles in the implementation which leads to government failure as the results of government intervention may not be able to truly solve the problem and raise adverse side effects. On the other hand, the government public financial expenditure has become increasingly difficult where the limited government budget on infrastructures is unable to meet the public's expectation. Therefore, it is essential for the government to not only reasonably allocate and control various budgets with efficiency and but also actively bring in the private investment in terms of the internalization and higher self-liquidating part of external benefit of infrastructure, which is the important method to reduce the unemployment rate and simultaneously expand the infrastructures under the financial shortage.

\subsection{Research Objectives}

This research used "Sun Moon Lake Hsiangshan/Xiangshan Tourism Hotel BOT Project" as a case study. Nantou County has beautiful scenery and many famous tourist attractions. But due to some irresistible force factors such as typhoons and earthquakes, it leads to some failures in Nantou tourism industry. Because the characteristics of infrastructure investments are large number of capital investment, high risk, slow recovery, and etc., how the involved private sectors shall master the business opportunities? So when to make decision and what decision shall be made and the calculation of the project valuation of BOT model, are the questions to be explored in this research. Real options approach provides a brand-new way of thinking and operation method in dynamic management model for decision makers when they make evaluation on decisions. Different from the conventional capital budgeting evaluation, Real options evaluation method adapting the techniques developed for financial options to help the decision makers apply the management flexibility method under uncertainty to "real-life" decisions. From the financial perspective, this study adopted the real option evaluation approach and management flexibility strategy based on the change of the market situation, to establish the optimal investment project management valuation as an alternative new thinking mode of BOT model of market strategy evaluation.

The purposes of this research are how to avoid downside risks of investment project and improve the response ability of decision makers under uncertainty and hence to explore the decision making threshold value of second stage of tourism hotel investment project by adopting real options approach under the process of the management flexibility. That is, using the real options approach of decision making evaluation model to create the optimal hurdle rate of second stage of investment decision making on the private enterprises involved infrastructures. Under condition of uncertainty income, it applied management flexibility strategy to provide references for investment decision making when private enterprises participate in public infrastructure in terms of decision evaluation models such as optimal hurdle rate and investment project valuation. The following are the purposes of this study:

1). To understand BOT related issues such as development origin, operation risks, and the differences from the general investment projects through literature review.

2). To investigate how to apply real options evaluation theory to the evaluation of private enterprises involved tourism hotel BOT project.

3). To compare the differences between Net Present Value (NPV) method and real option valuation approach (ROA).

4). To apply the real options theory to the investment appraisal BOT project by taking Sun Moon Lake Hsiangshan/Xiangshan Tourism Hotel BOT Project as a case study in order to make correct evaluation of this case. 


\section{Literature Review}

\subsection{Traditional Financial Evaluation Indicators and Real Option Analysis}

In general, the most frequently used traditional evaluation techniques to capital budgeting decision include the Internal Rate of Return (IRR), Discounted Cash Flow (DCF) Approach, Net Present Value (NPV) approach, and payback period method, etc.

(1) The Internal Rate of Return (IRR): Similar with NPV method, the IRR method is defined as the discount rate (IRR $=r$ value) that gives a NPV of zero. The IRR means when the net present value of future cash flow of investment project equals to the discount rate of the initial investment cost. If the independent project that has an IRR higher than the required rate of return (RRR) should be accepted.

(2) The Discounted Cash Flow (DCF) approach: DCF approach is a method of valuing a project, company, or asset using the concepts of the time value of money. All future cash flows are estimated and discounted by using cost of capital to give their present values (PVs). The sum of all future cash flows, both incoming and outgoing, is the net present value (NPV), which is taken as the value or price of the cash flows in question.

(3) The Net Present Value (NPV) method: The NPV of an investment is determined by calculating the present value (PV) of the total benefits and costs which is achieved by discounting the future value of each cash flow. When the NPV is $>0$, the investment project is feasible. For alternative investment projects, the project with the highest NPV should be pursued.

(4) Payback Period Method: payback period method is a simple capital evaluation method. It refers to the period of time required to recoup the funds expended in an investment, or to reach the break-even point. It focuses on the capital recovery rate to evaluate if the investment project is acceptable.

Arnold and Hatzopoulos (2000) pointed out that the most frequently used capital budgeting technique is NPV approach. The traditional NPV of an investment is determined by calculating the PV of the total benefits and costs which is achieved by discounting the future value of each cash flow. When the NPV is $>0$, the investment project shall be implemented, otherwise waive. The decision point is dependent on the estimated results of data for decision evaluation under the static and certain conditions. Although the calculation of NPV is easy with considering the time of money, the NPV method is the assumption of irreversible and retrieved investment. Under this assumption, most investment behavior cannot be changed and no flexibility, however, under the uncertain economic environment, how to make profit should put the focus of the management under the future uncertain conditions if the management flexibility can avoid downside risks and improve the NPV of project investment strategy which are the decision problems facing for enterprises.

Therefore, if a company to make investment or delay correction investment decisions, then the NPV method is not applicable; Dixit and Pindyck (1994) highlighted that the NPV approach does not adequately and explicitly consider management's ability to influence project outcomes through such measures as delay, staged development, or other appropriate responses to deal with uncertainty on capital projects. The reason is that the NPV neglects the existence of the flexibility value and therefore the evaluation of the project valuation with the traditional NPV would underestimate the real value and the underlying decision value. In general, the investment scheme has the following characteristics: (1) investment is irreversible or partially irreversible; (2) the investment environment is uncertain; (3) investment program implementation can be delayed, shutdown, restart or give up; with the application of management flexible strategy option, it can create investment plan strategy value, so the investment project value should include the traditional NPV value, plus the option value of flexible management. Ross (1995) pointed out, investment scheme of NPV >0, only represents the investment plan in the money; on the contrary, NPV $<0$, only represents the investment plan out of the money, but it does not mean that this investment project is of no value to be given up, because this may lead to statistic type I and type II error which is to refuse the project that should be accepted or accept the project that should be rejected, so these can lead to the loss caused by wrong judgement. In addition, Hayes and Garvin (1982) indicated that the decision on NPV discount rate is difficult, and it is often underestimated; and Trigeorgis and Mason (1987) pointed out that the traditional NPV method ignored or cannot adequately measure when uncertainties are different from the expectations, the managers is lack of ability to adjust business strategy. Therefore, investment plan proposition should consider strategic NPV (SNPV) including the option value generated by the traditional NPV and the management flexibility (strategic present value; SPV).

Real option model was originally developed by Black and Scholes (1973) which describes the European-style pricing equity options and presents a portfolio analysis framework of risk-free arbitrage model. The model had a huge influence on the financial research and long-term development of trade options. In recent years, real 
options theory and concept are widely applied in the fields of politics, the exploitation of natural resources, the merger of enterprises and operation, and risk management, etc. Real options is the flexibility in strategic decision-making when manager makes "continuously" respond to market changes. The biggest differences between real options and options are that the underlying subject of the options is real entity and the underlying subject of real options is intangible. Luehrman (1998) pointed out that the difference between real options and NPV method is from flexibility perspective of the investment project. One investment project has the possibility of deferred decision-making which can bring two kinds of value: (1) the time value of money: deferred decision can avoid early investment capital, and this capital can obtain interest income. The implemented price of Real options model is presented as the risk-free discount interest rate, while NPV rules are not applicable. (2) Risk avoidance: during the waiting period for the decision, the environment may become favorable for the investment to maximize the interests of asset value which can urge the enterprise to implement the investment plan; if the conditions become unfavorable, the company shall choose to quit this plan, so it can produce the value when reducing the risks. And hence the value raised by the uncertainty of future investment environment can be represented as variance and the variance can express for various weighted average deviations of possible conditions. Therefore, this characteristic shall be fully considered in the application of options model while the traditional NPV is unable to express this variation.

The related research on the application of real options method in tourism and leisure industry.

Chen (2001) adopted SWOT analysis on investment project of Penghu international tourism hotel and NPV approach to assess the project valuation and the results showed that the project is most valuable when the government agreed to attached casino facilities and allowing the foreigner visitors to enter, which provides relevant government units for decision-making as reference. Chang and Shih (2004) adopted ROA with entry modes with reference of dynamic decision-making evaluation on international hot spring hotels through data analysis and simulation analysis to present more clearly the differences between ROA and NPV. Fu, Chang, and Shi (2005) adopted management flexibility strategy under uncertain business income to calculate the optimal entry hurdle value in regards to the private tourism hotel enterprises involved the investment of Penghu international tourism hotels and assess optimal investment project value for the reference of investment decision-making. Also, they considered the effects of unexpected events on the investment project of tourism hotels, to explore its effect on market entry strategies and project value assuming that the unexpected events follow Poisson process. Shih, Chang, and Fu (2006) used ROA to investigate private hot spring enterprisers enter and exit the Taiwan market under the uncertain income for the reference of investors' dynamic decision-making evaluation, and to compare the difference between the traditional NPV method and ROA. Furthermore, Chiu, Hsiao, and Chou (2008) evaluated the optimal investment decision of the tourism industry of Taiwan with the ROA under uncertain income and the number of passengers. They assumed that the tourism income and the number of passengers follow geometric Brown motion, and used the equivalence and smooth condition to calculate the optimal investment threshold value and tried to construct the optimal investment decision criteria of tourism industry. Ho and Jaw (2010) constructed a model that based on the real options analysis for dealing with the entry-exit strategies of cosmetic GMP certification. And they compared the difference between the risk-adjusted NPV and real options. Yeh et al. (2017) evaluated the sensitivity analysis of the real estate development option showed that the higher the current price, the volatility of real estate price, the change rate of real estate price, the time to expiration, the land value sustainable factor, and the volatility of land price, the higher the extended NPV is. However, the higher the strike price, the correlation coefficient between the land price and the total sales amount of real estate, the current price of land, and the required rate of return, the smaller the extended NPV.

\subsection{The Evaluation of BOT Investment Project}

In order to enhance the investment of private capital, improve operation efficiency and reduce the financial burden of the government, the government promulgated the "Regulations for promotion of private participation in public infrastructure" (Regulation) on $9^{\text {th }}$ February, ROC year of 89 (2001), to actively promote the private participation in public infrastructure. According to the regulation of Article 8, in the BOO (Built-Operate-Own) framework, the public administration delegates to a private sector entity to purchase land and design and build infrastructure and to operate and maintain these facilities for a certain period. The private party will be the owner of the regarded facility and no need to transfer to the public administration at the end of the concession agreement, and can maintain to operate the facility or sell shares in the capital market or pursue other investors to cooperate. A BOO scheme involves large amounts of finance, long construction period, low return rate and other uncertain factors, so it implies higher investment risks in construction and operation period than other general investment projects. 
Liu et al. (2000) explored the different risk level of BOT model in staged construction contract which are (a) the first stage is planning period, the major works include fund raising, construction planning, and investment attraction; (b) the second stage is the construction period, the key work involves construction management, how to effectively control the completion date, and construction quality and construction cost; (c) the third stage is the operation period, the main work include the maintenance of operational quality, profit, operating cost overruns and the market demand risk. Guo (1998) pointed out that private enterprises involved infrastructure relates the issues such as the engineering technology, financial planning, risk taking, political and legal, and team integration, etc., among which the most dangerous risk is financial risk because the implementation of financial funds scheduling can influence the success or failure of the investment project.

For the real option research on the application of BOT, In Rose's (1998) study, it took BOT high-speed railway project in Australia Melbourne as an example, and it assumed when the IRR of after tax income of chartered manufacturers was higher than a fixed rate, the government has the right terminate the concession period in advance, but at the same time the government gave the chartered manufacturers the rental payment deferred right which are used to analyze the government recovery value, the deferred value of chartered manufacturers, and the value in both of terms. In addition, Lin (2000) used BOT development project in Tamkang Bridge as a case study, based on cash flow simulation model as the benchmark of the self-liquidating ratio and investment return rate, it conducted a static financial analysis and sensitivity analysis in project income and concession scope in order to the changes of key variables influencing on the finance. And it analyzed the impact on NPV of the project with changes in future investment under the proposed strategy. Lin and Ko (2003) used the ROA to investigate the Kaohsiung MRT project, the simulation results of operation value is excessive the management flexibility value to NPV, and proposed three kinds of surplus distribution strategy to pursue the profit maximization of public infrastructure project in order to achieve 3-win strategy between government, private sectors and enterprises. Huang and Chou (2006) used a minimum income guarantee (MRG) as a European-style option, combining with the give up (before the construction) option to be a compound option and took an empirical research in Taiwan high-speed railway. The findings of the research showed that increasing the MRG can reduce the give-up option value, so that when MRG is higher at a certain level, there was no longer value in give-up option.

\subsection{Sun Moon Lake National Scenic Area}

Nantou County is located in central Taiwan within a total of 13 villages and towns, and it has a population of 530,000 people. There are many beautiful scenery and many famous tourist attractions in the County, such as Sun Moon Lake, Yushan National Park, rich natural landscape of the mountains, springs, lakes, and Taiwan exclusive ecological resources like precious unique species of animals and plants etc. Moreover, there are three major mountains in the County which are the Central Mountain Range, Yushan Mountains and Ali Mountains. Also, the area of landscape is about 1/8 of whole area of the County, including five major tourism routes, such as "Sun Moon Lake Tour", "Clear View of Mount Lu Tour", "Chi-tou Sanlinchi Tour", "Mount Yu Tongpu Tour" and "Mount Bagua Maoluo River Tour". Furthermore, there are four native aborigines tribes living in the County which are the Atayal, the Bunun, the Tsou, and the Thao, and hence Nantou County has diverse and rich culture, and different scenic spot features with different strong aborigines' custom and style, and thus become a prime tourism destination in Taiwan.

Sun Moon Lake, situated in Nantou County's Yuchi Township near the center of Taiwan, is the island's largest lake with the total area of 7.93 square kilometers (8.4 square kilometers at full water level), depth of 27 meters, and 748 meters above sea level. Crowned as one of the Eight Wonders of Taiwan, the island on Sun Moon Lake was the ancient settlement of the Thao people. The Pingpu tribe used to call the native aborigines as "shalian", and the area of Sun Moon Lake with the inter Mountains is the largest group of water basin, so the original name of Sun Moon Lake was "shueishalian". In 1970, Sun Moon Lake was granted as provincial scenic area, and after 921 Earthquake of 1999, the government has done reconstruction and designed new service projects. The Sun Moon Lake National Scenic Area Administration Office was established in January 2000. It lies at the center of Nantou County, connecting Puli Township in the north to Renai Township in the northeast, Xinyi Township in the southeast, Shuili Township in the southwest and Guoxing Township in the northwest.

In recent years, in order to boost the overall development of the domestic and foreign tourism and leisure industry, the government has included the Sun Moon Lake as one of the major investment projects and at the same time has started planning "double tourists plan". The overseas tourists can increase to more than 2,000,000 people/year, while the total number of foreign visitors has grown to 5,000,000 people/year. Currently, there are a total of five main package tourism routes in Taiwan and the "Sun Moon Lake Tour" located in center of Nantou County is one of them. With the implementation of two days off every week, the enjoying the leisure time has 
become popular in Taiwan and then stimulates the development of tourist attractions and investment in tourism related industries, such as hotels, restaurants, guesthouses, leisure farms and large-scale amusement parks. In addition, in order to improve the standard of rural living, every municipal government has assisted the rural regeneration and agricultural transformation to open up the source of fiscal revenue, and start to have expenditure on tourism and leisure industry to develop special tourism patterns. The increased number of tourists due to Double Tourists Plan has caused the growth of actual demand of tourism hotels. Every government has to invest their resources to expand. However, under the limited government budgets and in the face of highly competitive exclusion from other counties and cities, how to make full utility of the existing tourism resources to develop a more innovative tourism and leisure industry is the research problem to future tourism development project of Nantou County.

The case used in this research is sponsored by the MOTC, the administration office of Sun Moon Lake National Scenic Area was authorized to take "Sun Moon Lake Hsiangshan/Xiangshan Tourism hotels BOT Project" into effect in January 98 (2010). The current the number of hotel rooms of Sun Moon Lake surrounding area is 2,194, and while the accommodation demand forecast for ROC year of 101 (2013) was expected to 3,336 rooms, and hence the current accommodation facilities of Sun Moon Lake area have been unable to meet the future demand. Therefore, in terms of long term development plan, the management office of the Sun Moon Lake national scenic area has commenced to plan on development project of Sun Moon Lake Hsiangshan/Xiangshan tourism hotelss expecting to attract private investments through BOT method in order to enhance the tourism development of Sun Moon Lake and strengthen international level of service standards.

The Hsiangshan/Xiangshan area is an untapped virgin land on the west side of Sun Moon Lake and then segmented into two bases as "The Land For Tourist Service Center" and "Exclusive Zone For Tourism Industry" through Sun Moon Lake National Scenic Area Administration planning, wherein the "Exclusive Zone For Tourism Industry" can be encouraged in the way of BOT and be invested by the private investments in construction of tourism and recreation facilities including accommodation and restaurants. This case covers 2.7949 hectares as the tourism exclusive zone with the coverage rate of $40 \%$ and the volume rate of $120 \%$, allowing usage items including outdoor recreation facilities, tourism service management facilities, sightseeing platform, hiking trails, parking, retail, accommodation, catering and other approvals by the central tourism authority. Based on the business plan of the investment project, it has two stages of development, the first stage of investment is expected to NT \$1.2 1.3 billion to construct a tourism hotel with 265 guest rooms at average room rate of NT $\$ 3,979$ positioning as the group visitors hospitality hotel, national tourism resort, resort and meeting center, wedding manor and performing experience hall. Except for the guest rooms, it offers other attributes of commercial facilities, such as restaurants, meeting rooms, lounge bar, retail shops and souvenir shop; the second stage investment is expected to NT $\$ 500$ million to construct 101 high-quality luxury rooms including villa and clubs. The total investment is expected to amount to NT $\$ 1.92$ billion with 4 years of the construction period and 46 years of operation period.

The development of this case will create more than a hundred of employment opportunities and increase the accommodation supply of Sun Moon Lake area which can alleviate the problem of insufficient accommodation in Sun Moon Lake holiday area, and will become a world-class landscape architecture by merging with the completion of Hsiangshan/Xiangshan administrative center in the future. And also Sun Moon Lake national scenic area administration office has made planning on the overall future development of surroundings and planed the ropeway system of Hsiangshan/Xiangshan - Checheng on east side of the road of the 21 line, connecting with subline of Taiwan Railway, high-speed railway, and westlink of Taiwan Railway which enhances the accessibility of Sun Moon Lake traffic; the existing plan for Huantan bike and hiking trails will be extended to the Hsiangshan/Xiangshan area and combing with the future plan of Hsiangshan/Xiangshan park and pier, and linking to Hsiangshan/Xiangshan recreation area to complete a whole recreation belt for tourists to experience different transportation modes and it can provide different recreational experience to create the Sun Moon Lake resort for leisure travel at international level.

\section{Research Method}

This research adopted ROA to construct optimal investment decision criteria of tourism hotel industry under the uncertain income through the basic framework model from Lin and Shih (2002) and expanded entry and exit models from Lin and Shih (2003) to assess the project value. And applying Dixit and Pindyck (1994) value matching condition and smooth pasting condition to data analysis and stimulation analysis the optimal entry and exit threshold for the concession company. 


\subsection{Stimulation Analysis}

According to the data from Tourism Bureau, M.O.T.C. Republic of China (Taiwan) during 1999 to 2008, show as Table 1. Applying polymath 6.1 to solve the optimal entry and exit thresholds for the concession company. First of all, to calculate $\beta_{1}$ and $\beta_{2}$, show as Table 2 .

Table 1. Relevant variable and parameters

\begin{tabular}{lcc}
\hline Parameter & Data & Resource \\
\hline Investment Cost $I$ & $I=200$ & Sun Moon Lake Hsiangshan/Xiangshan Tourism hotels BOT Project \\
Exit Cost $E$ & $E=30$ & Assumption \\
Operating Cost $C$ & $C=90$ & Assumption \\
Stand Deviation $\sigma$ & $\sigma=0.1032$ & Tourism Bureau, M.O.T.C. Republic of China (Taiwan) during 1999 to 2008 \\
Growth rate $\alpha$ & $\alpha=0.0612$ & Tourism Bureau, M.O.T.C. Republic of China (Taiwan) during 1999 to 2008 \\
Risk-free interest rate $r$ & $r=10 \%$ & Central Bank of the Republic of China (Taiwan) ten-year bond rate \\
$\begin{array}{l}\text { Expected return } r m \\
\text { The coefficient correlation of }\end{array}$ & $r m=1 \%$ & Assumption \\
capital market portfolio $\rho_{\Psi m}$ & $\rho_{\Psi m}=1$ & Assumption \\
\hline
\end{tabular}

Table 2. Parameter $\beta_{1}$ and $\beta_{2}$

\begin{tabular}{lcc}
\hline Parameter & Calculation & Result \\
\hline$\beta_{1}$ & $\beta_{1}=\left(\frac{1}{2}-\frac{\delta}{\alpha^{2}}\right)+\sqrt{\left(\frac{\delta}{\alpha^{2}}-\frac{1}{2}\right)^{2}+2 \frac{r}{\alpha^{2}}}$ & 6.71166312 \\
$\beta_{2}$ & $\beta_{2}=\left(\frac{1}{2}-\frac{\delta}{\alpha^{2}}\right)-\sqrt{\left(\frac{\delta}{\alpha^{2}}-\frac{1}{2}\right)^{2}+2 \frac{r}{\alpha^{2}}}$ & -6.82341272 \\
\hline
\end{tabular}

Parameters are substituted into the model to simulate the optimal entry and exit thresholds, and the solutions are derived as follows:

Table 3. Optimal entry-exit thresholds

\begin{tabular}{lcccc}
\hline Model & $\begin{array}{c}\text { Entry Thresholds } \\
\text { (billion NT dollars) }\end{array}$ & $\begin{array}{c}\text { Exit Thresholds } \\
\text { (billion NT dollars) }\end{array}$ & Coefficients A & Coefficients B \\
\hline Risk-adjusted NPV Model & 804.34 & 783.54 & - & - \\
Entry Model & 1731.69 & - & -14.52 & - \\
Entry-Exit Model & 1676.20 & 689.58 & -14.52 & 399.12 \\
\hline
\end{tabular}

From the outcome of the empirical analysis, the value of managerial flexbility is determined as follows:

Table 4. Strategic value of managerial flexibility (billion NT dollars)

\begin{tabular}{lccc}
\hline Model & Strategic NPV & Basic NPV & SPV \\
\hline Entry Model & 1731.69 & 804.34 & 927.35 \\
Extended Model (Entry) & 1676.20 & 804.34 & 871.86 \\
Extended Model (Exit) & 689.58 & 783.54 & -93.96 \\
\hline
\end{tabular}

1) The risk-adjusted NPV model: the optimal entry and exit thresholds of the risk-adjusted NPV model are 804.34 and 783.54 billion NT dollars.

2) The entry model: the difference, 927.35 billion NT dollars, between the potential entry strategic value of the project 1371.69 billion NT dollars and the value of the risk-adjusted NPV model 804.34 billion NT dollars is the potential entry value of the real option.

3) The entry-exit model: the difference, 871.86 billion NT dollars, between the potential entry strategic value 
of the project 1676.20 billion NT dollars and the value of the risk-adjusted NPV model 804.34 billion NT dollars is the potential entry value of the real option. The same situation applies for the difference, -93.96 billion NT dollars, between the strategic exit value of the project 689.58 billion NT dollars and the value of the risk-adjusted NPV model 783.54 billion NT dollars, which is the potential exit value of the real option

Taking the entry and exit model as an example, a table and graph of the potential entry strategic value of the project, $V_{0}(\pi)$, and the value of executing the project, $V_{1}(\pi)$, can be presented, as follows:

Table 5. The project value of the entry-exit model

\begin{tabular}{lcccc}
\hline & \multicolumn{2}{c}{ Entry model } & \multicolumn{2}{c}{ Entry and exit model } \\
\cline { 2 - 5 } The optimal threshold & $V_{0}(\pi)$ & $V_{1}(\pi)$ & $V_{0}(\pi)$ & 615.76 \\
\hline 689.58 & - & - & 647.08 & \\
1000 & 1762.07 & & 1762.07 & 3723.71 \\
1500 & 2672.71 & - & 2672.71 & - \\
1676.20 & - & 3809.99 & 3523.71 & 4678.80 \\
1731.69 & 3607.89 & 4644.60 & - & 5431.49 \\
2000 & & 5428.79 & & \\
2500 & & & & \\
\hline
\end{tabular}

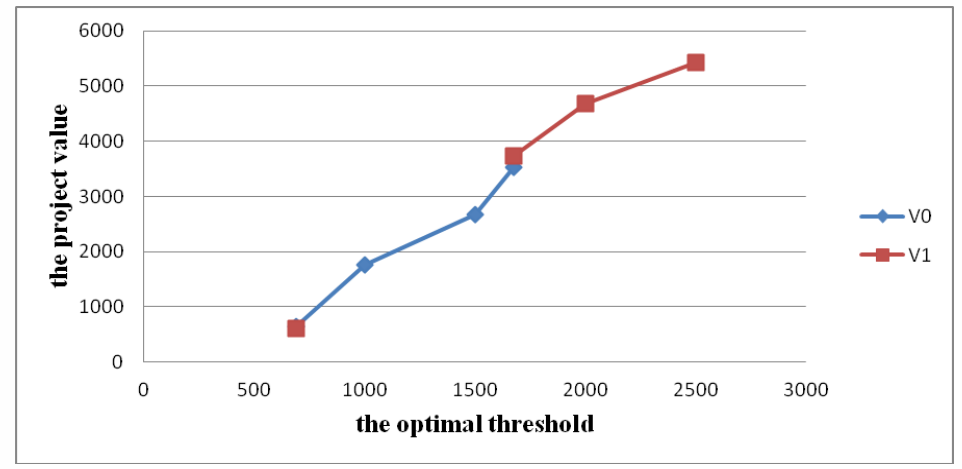

Figure 1. The Entry-Exit Model in $V_{0}(\pi)$ and $V_{1}(\pi)$

Figure 1 displays the optimal entry and exit thresholds. Observe that at the optimal exit threshold, 689.58 billion NT dollars, $V_{0}(\pi)$ exceeds $V_{1}(\pi)$ by the abandonment cost of 30 billion NT dollars, since this time is the optimal time for exercising the abandonment option, $V_{0}=V_{1}+E$. Likewise, at the optimal entry threshold, 1676.20 billion NT dollars, $V_{1}(\pi)$ exceeds $V_{0}(\pi)$ by the investment cost of 200 billion NT dollars, since this time is the optimal time to invest. So $V_{1}=V_{0}+I$.

\subsection{Sensitivity Analysis}

This section examines how related parameters influence the optimal entry and exit thresholds.

\subsubsection{Dependence of the Entry and Exit Thresholds Increase with Investment Cost}

Table 6. Dependence of the thresholds with investment cost

\begin{tabular}{lcccc}
\hline Investment cost & Optimal entry threshold & Optimal exit threshold & A1 & B2 \\
\hline 210 & 1691.44 & 681.74 & -14.54 & 399.22 \\
205 & 1683.82 & 685.62 & -14.53 & 399.17 \\
200 & 1676.20 & 689.58 & -14.52 & 399.12 \\
195 & 1668.58 & 693.63 & -14.51 & 399.08 \\
190 & 1660.97 & 697.76 & -14.51 & 399.03 \\
\hline
\end{tabular}




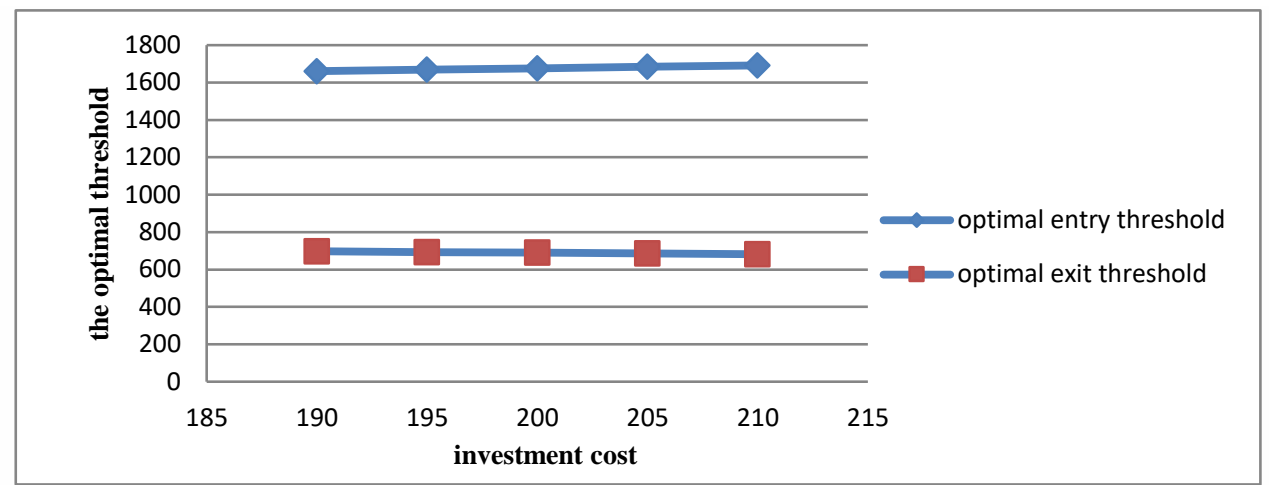

Figure 2. Dependence of the thresholds with investment cost

Increasing the investment cost increases the optimal entry threshold. Table 6 and Figure 2 show that the optimal entry threshold increases with investment cost (from 1660.97 to 1691.44 billion NT dollars), but the optimal exit threshold declines with investment cost (from 697.76 to 681.74 billion NT dollars).

3.2.2 Dependence of the Entry and Exit Thresholds on Abandonment Cost

Table 7. Dependence of the thresholds with abandonment cost

\begin{tabular}{lcccc}
\hline Abandonment cost & Optimal entry threshold & Optimal exit threshold & A1 & B2 \\
\hline 40 & 1676.204 & 671.801 & -14.5239 & 399.8587 \\
35 & 1676.203 & 680.6234 & -14.5239 & 399.1477 \\
30 & 1676.203 & 689.5795 & -14.5239 & 399.1233 \\
25 & 1676.203 & 698.6737 & -14.5239 & 399.098 \\
20 & 1676.202 & 707.9105 & -14.5239 & 399.0717 \\
\hline
\end{tabular}

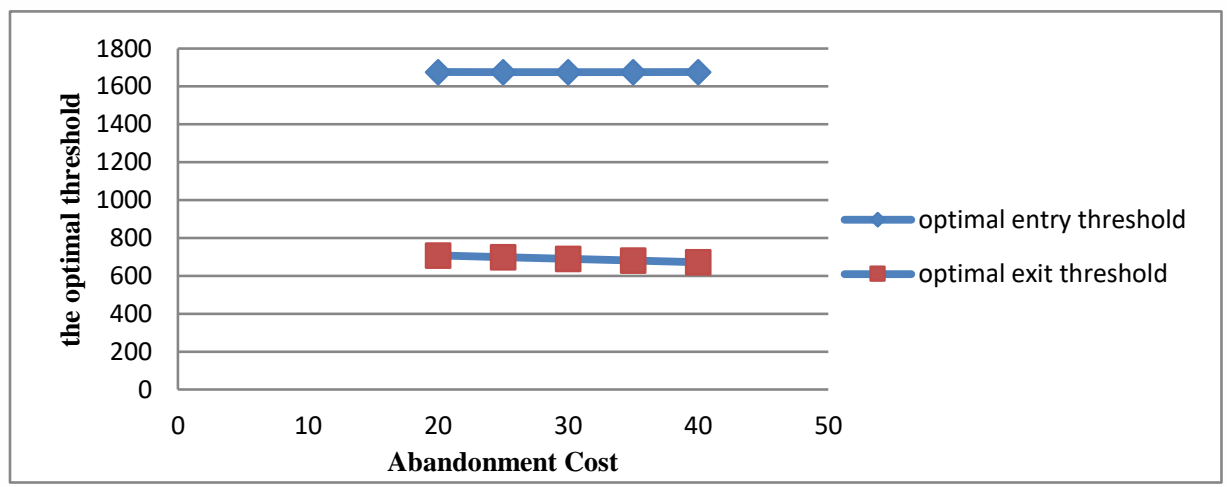

Figure 3. Dependence of the thresholds with abandonment cost

An increase in the abandonment cost reduces the exit threshold (from 707.91 to 671.80 billion NT dollars); meaning that the investor must pay more to exercise its abandonment option, and that the threshold must fall before it is willing to abandonment this business.

\subsubsection{Entry and Exit Thresholds as Functions of the Volatility Parameter}

Table 8. Volatility parameter influences the optimal thresholds

\begin{tabular}{lcccc}
\hline The degree of variation risk & Optimal entry threshold & Optimal exit threshold & A1 & B2 \\
\hline 0.1052 & 1950.42 & 764.45 & -15.21 & 248.84 \\
0.1042 & 1808.12 & 726.05 & -14.53 & 307.44 \\
0.1032 & 1676.20 & 689.58 & -14.52 & 399.12 \\
0.1022 & 1549.17 & 647.19 & -3.61 & 518.14 \\
0.1012 & 1428.60 & 598.90 & -1.52 & 672.65 \\
\hline
\end{tabular}




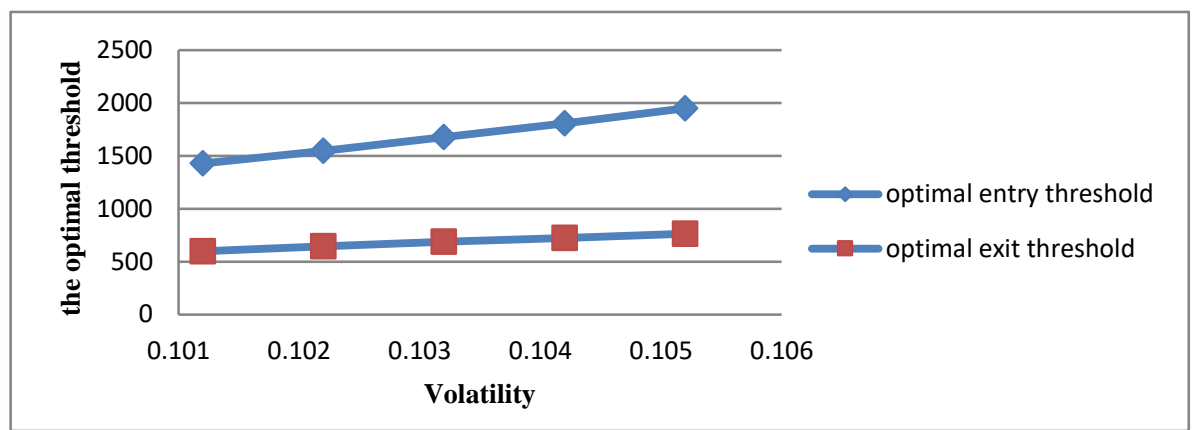

Figure 4. Volatility parameter influences the optimal thresholds

From Table 8 and Figure 4, an increase in the standard deviation of the growth rate of the operating income will increase the optimal entry and exit thresholds. When volatility equals 0.1012 , we can get the optimal entry and exit thresholds 1428.60 and 598.90 billion NT dollars. When volatility equals 0.1052 , we can get the optimal entry and exit thresholds 1950.42 and 764.45 billion NT dollars. Consequently, moderate uncertainty causes a significant increase in the zone of inaction from 829.7 to 1185.97 . Observe that this zone increases with volatility.

3.2.4 Dependence of the Entry and Exit Thresholds on Operating Cost

Table 9. Dependence of the thresholds on operating cost

\begin{tabular}{lcccc}
\hline Operating Cost & Optimal entry threshold & Optimal exit threshold & A1 & B2 \\
\hline 100 & 1828.59 & 791.16 & -14.63 & 399.21 \\
95 & 1752.39 & 740.09 & -14.58 & 399.23 \\
90 & 1676.20 & 689.58 & -14.52 & 399.12 \\
85 & 1600.01 & 639.68 & -14.47 & 399.21 \\
80 & 1523.82 & 590.42 & -14.41 & 398.75 \\
\hline
\end{tabular}

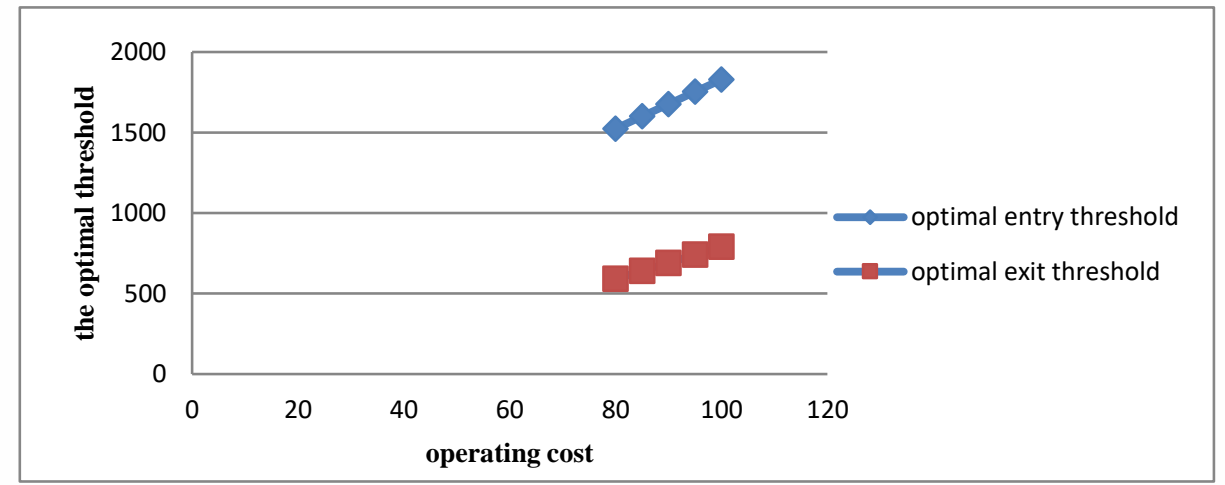

Figure 5. Dependence of the thresholds on operating cost

Table 9 and Figure 5 illustrate the dependence of the entry and exit thresholds on operating cost. Both the entry (from 1523.82 to 1828.59 billion NT dollars) and exit (from 590.42 to 791.16 billion NT dollars) thresholds increase with operating cost. Higher operating cost reduces the expected cash flows, and hence project value, meaning a higher threshold is required before a firm is willing to invest. Additionally, the firm will abandon this business at a higher threshold, because its losses increase with higher operating cost.

\section{Conclusion and Suggestions}

A successful private participated public infrastructure project must depend on mutual cooperation between the public and private sectors where the public sector must conduct comprehensive preparation and then select the most appropriate manufacturers from the private sector through the principle of fairness and justice, and it is important for the private sectors to have a sound management to coordinate various aspects of financial, 
technology, and the construction. Therefore, on the one hand, the private involved infrastructure can reduce the government's financial burden and also bring the business opportunities to construct and operate the infrastructures in an efficient way. And therefore, if it is implemented properly, the project can create multiple win-win situations for society. In addition, the BOT project has a large amount of investment, high risk, and long duration period investment, and the underlying subject of the project is very unique, no example and difficult to measure. Therefore, it may be often easy to make wrong decision-making in terms of analysis and plan of overall business strategy through the traditional financial information. So this research adopted ROA to construct optimal investment decision criteria of tourism hotel industry under the uncertain income through the basic framework model from Lin and Shih (2001) and expanded entry and exit models from Lin and Shih (2002) to assess the project value.

\subsection{Empirical Results}

It is necessary for public investment projects to first consider its necessity and the feasibility. As the self-liquidation ratio can influence on the willingness of participation in infrastructures for private sectors, that is, when self-liquidation ratio of the project is high, and with strong commercial property and high private investment incentives, if the assessed project is feasible, then it can start to the construction under permission mode of private participation model from the Regulation. The contribution of this study is to use the private sector involved Sun Moon Lake Hsiangshan/Xiangshan Tourism Hotel BOT Project with ROA under uncertain income to obtain the optimal threshold value and to evaluate the optimal investment project value. From the relative literature review of regulation, customer relationship, and corporate governance models, this study investigated the investment decision-making timing of tourism hotels. The results of the study found that the increase in cost of investment, exit cost, risk variation, operation cost, and the risk free interest rate, can lead to unfavorable to the investment and they have significant positive relationship with optimal threshold value which reflects the characteristics of options, that is, the changes of future environmental can lead to the increase of investment threshold value and decrease of investment willingness of private sectors involvement. Therefore, the concession company can evaluate if it reaches to the optimal value, the company can participate in the investment. Otherwise, when the project investment is unfavorable, the company should suspend the investment and make an exit to avoid the waste of social costs. So this study adopted the relative information through data analysis and stimulation analysis to clearly show the differences between ROA and traditional NPV.

\subsection{Managerial Implications}

Based on the above data analysis of the empirical results, some managerial implications of theoretical model are proposed for the concession company to evaluate investment decisions as references.

1). When the required investment costs of the concession company involved infrastructure has risen, it is relatively unfavorable for the investment and the threshold value will increase.

2). When the exit cost of participated project has increased, it means that the concession company's give-up option value will decrease, so the valuation of the project dropped which is that the lower exit cost is, the higher the optimal threshold value.

3). The degree of variation risk has increased, the risk of the involved project will grow, and therefore, the requirements of the optimal threshold value will increase.

4). When operating costs of the involved project has increased, it will reduce the project value and cash flow, which is not relatively unfavorable to the investment, and hence the optimal threshold value shall grow higher.

\section{References}

Arnold, G. C., \& Hatzopoulos, P. D. (2000). The theory-practice gap in capital budgeting: Evidence from the United Kingdom. Journal of Business Finance and Accounting, 27(5/6), 603-626. https://doi.org/10.1111/1468-5957.00327

Black, F., \& Scholes, M. (1973). The pricing of options and corporate liabilities. Journal of Political Economy, 81, 637-659. http://dx.doi.org/10.1086/260062

Chang, K. C., \& Shih, T. L. (2004). A Study on the investment decision-making of hot spring tourism and recreation industries in Taiwan. Taiwan Bank Journal Quarterly, 55(4), 212-226.

Chen, A. B. (2001). Evaluation of investment risk of international tourist hotel in Penghu (Unpublished d master thesis). National Taiwan University of Science and Technology, Taipei.

Chiu, C. H., Hsiao, H. D., \& Chou, H. P. (2008). The optimal investment decision in tourism industry under uncertainty. FarEast Review, 25(2), 391-400. 
Dixit, A. K., \& Pindyck, R. S. (1994). Investment under uncertainty. Princeton: Princeton University Press. https://doi.org/10.1515/9781400830176

Fu, P. H., Chang, K. C., \& Shih, T. L. (2005). The financial decision making for international tourist hotel in Penghu: The application of real options approach. Service Industry Management Review, 1(2), 117-132.

Hayes, R., \& Garvin, D. (1982). Managing as if tomorrow mattered. Harvard Business Review, 60, 71-79.

Ho, S. H., \& Jaw, K. S. (2010). Applying real options in investment decision of cosmetic GMP certification. The Journal of International Esthetic Science, 7(4), 47-64. http://dx.doi.org/10.30001\%2fJIES.201012.0004

Huang, Y. L., \& Chou, S. P. (2006). Valuation of the minimum revenue guarantee and the option to abandon in bot infrastructure projects. Construction Management and Economics, 24(4), 379-389. https://doi.org/10.1080/01446190500434997

Lin, C. M. (2000). The study on the BOT dynamic financial analysis-applied to Tamchiang Bridge (Unpublished master thesis). National Kaohsiung First University of Science and Technology, Kaohsiung.

Lin, D. R., \& Shih, T. L. (2003). Entry-exit strategies in a competitive market under insurance premium uncertainty: Applying real options. Journal of Project Management, 1(1), 11-25.

Lin, T. T., \& Ko, C. C. (2003). Application of BOT model for Kaohsiung MRT project using real options with income uncertainty. Transportation Planning Journal Quarterly, 32(1), 151-175. http://dx.doi.org/10.6402\%2fTPJ.200303.0151

Lin, T. T., \& Shih, T. L. (2002). The entry decision in Chinese life insurance market under the premium uncertainty: An application of real options in competitive market. Journal of Risk Management, 4(2), 61-86. http://dx.doi.org/10.30003\%2fJRM.200211.0003

Liu, Y. R., Wang, W. Y., \& Huang, Y. L. (2000). Win-Win strategy for BOT. Shinning Culture Publishing Company.

Luehrman, T. A. (1998). Investment opportunities as real options: getting started on the numbers. Harvard Business Review, 76, 51-60.

Rose, S. (1998). Valuation of interacting real options in a toll road infrastructure project. The Quarterly Review of Economics and Finance, 23-717.

Ross, S. A. (1995). Uses, abuses, and alternatives to the NPV rules. Financial Management, 24, 259-270. https://doi.org/10.2307/3665561

Shih, T. L., Chang, K. C., \& Fu, P. H. (2006). The entry/exit real options model for the tourism industry: A case focusing on a hot springs resort in Taiwan. The Journal of Tourism Studies, 12(1), 1-22. http://dx.doi.org/10.6267\%2fJTLS.2006.12(1)1

Trigeorgis, L., \& Mason, S. P. (1987). Valuing managerial flexibility. Midland Corporate Finance Journal, 5(1), 14-21.

Yeh, I. C., Tseng, H. P., Kuan, Y. C., \& Hsieh, P. W. (2017). Evaluating the real estate development option: A hybrid approach of binomial options pricing model and Mote Carlo simulation. The Construction Management Journal, 107, 19-37. http://dx.doi.org/10.6505\%2fCMJ-2017-107-19-19

\section{Copyrights}

Copyright for this article is retained by the author(s), with first publication rights granted to the journal.

This is an open-access article distributed under the terms and conditions of the Creative Commons Attribution license (http://creativecommons.org/licenses/by/4.0/). 